\title{
Cholic Acid Biosynthesis
}

\section{THE ENZYMATIC DEFECT IN CEREBROTENDINOUS XANTHOMATOSIS}

\author{
Gerald Salen, S. Shefer, F. W. Cheng, B. Dayal, A. K. Batta, and G. S. Tint, \\ College of Medicine and Dentistry of New Jersey, New Jersey Medical School, \\ Newark, New Jersey 07103; Veterans Administration Hospital, East Orange, \\ New Jersey 07019; Cabrini Health Care Center, New York 10003; and Public \\ Health Research Institute of The City of New York, Inc., New York 10016
}

A B S T R A C T Cholic acid biosynthesis is defective in individuals with cerebrotendinous xanthomatosis (CTX) and is associated with the excretion of $5 \beta$ cholestane- $3 \alpha, 7 \alpha, 12 \alpha, 25$-tetrol, an intermediate in the 25-hydroxylation pathway of cholic acid in CTX. To define the enzymatic defect in CTX, two suspected precursors of cholic acid, namely $5 \beta-\left[7 \beta^{3} \mathrm{H}\right]$ cholestane- $3 \alpha, 7 \alpha, 12 \alpha$-triol and $5 \beta-\left[24-{ }^{14} \mathrm{C}\right]$ cholestane- $3 \alpha, 7 \alpha$, $12 \alpha, 24 S, 25$-pentol were examined by both in vivo and in vitro experiments. A third precursor, $5 \beta-\left[7 \beta-{ }^{3} \mathrm{H}\right]-$ cholestane-3 $\alpha, 7 \alpha, 12 \alpha, 25$-tetrol, was compared with them in vitro.

In the in vivo experiments, each one of the labeled precursors was administered intravenously to two CTX and two control subjects. In the controls, $5 \beta$-[7 $\beta$ $\left.{ }^{3} \mathrm{H}\right]$ cholestane- $3 \alpha, 7 \alpha, 12 \alpha$-triol as well as $5 \beta-\left[24-{ }^{14} \mathrm{C}\right]$ cholestane- $3 \alpha, 7 \alpha, 12 \alpha, 24 \mathrm{~S}, 25-$ pentol were rapidly converted to labeled cholic acid. Maximum specific activity values were reached within $1 \mathrm{~d}$ after pulse labeling, followed by exponential decay of the cholic acid specific activity curves. In contrast, these two precursors differed widely when administered to two CTX patients. While $5 \beta-\left[24-{ }^{14} \mathrm{C}\right]$ cholestane- $3 \alpha, 7 \alpha, 12 \alpha$, $24 \mathrm{~S}, 25$-pentol was rapidly converted to $\left[24-{ }^{14} \mathrm{C}\right]$ cholic acid and yielded identical decay curves with those obtained in the control subjects, maximum specific activity values in $\left[7 \beta^{3} \mathrm{H}\right]$ cholic acid were much lower and peaked only on the second day after the injection of $5 \beta-\left[7 \beta-{ }^{3} \mathrm{H}\right]$ cholestane- $3 \alpha, 7 \alpha, 12 \alpha$-triol. Furthermore, an appreciable amount of ${ }^{3} \mathrm{H}$ label was present in the $5 \beta$-cholestane- $3 \alpha, 7 \alpha, 12 \alpha, 25$-tetrol isolated from the bile of the subjects with CTX.

In the in vitro experiments, three enzymes on the 25hydroxylation pathway of cholic acid were examined in both control and CTX subjects. The rate of the 25hydroxylation of $5 \beta$-cholestane- $3 \alpha, 7 \alpha, 12 \alpha$-triol in CTX

Received for publication 17 July 1978 and in revised form 20 September 1978. patients was comparable to that in the controls. Similarly, the transformation of $5 \beta$-cholestane- $3 \alpha, 7 \alpha, 12 \alpha$, 24 S,25-pentol to cholic acid, catalyzed by soluble enzymes, proceeded at approximately equal rates in CTX and in control individuals. On the other hand, the rate of $5 \beta$-cholestane- $3 \alpha, 7 \alpha, 12 \alpha, 24 \mathrm{~S}, 25$-pentol formation was about four times greater in the control subjects than in the CTX patients.

The results of the in vivo as well as the in vitro experiments suggest that the site of the enzymatic defect in CTX is at the 24S-hydroxylation of $5 \beta$-cholestane-3 $\alpha, 7 \alpha, 12 \alpha, 25$-tetrol. The relative deficiency of this hydroxylase in CTX patients, accompanied by the accumulation of its substrate in bile and feces, probably accounts for the subnormal production of bile acids in CTX patients.

\section{INTRODUCTION}

Cholesterol is the obligatory precursor of bile acids in all vertebrates (1). In the last few years, considerable information has been accumulated concerning the biosynthetic mechanisms whereby the weakly polar molecule of cholesterol is transformed into the strongly polar bile acid molecule. The liver appears to be the sole organ capable of transforming cholesterol into bile acids. In man, the primary bile acids, i.e., those formed directly from cholesterol in the liver, are chenodeoxycholic acid and cholic acid. ${ }^{1}$ The most commonly accepted mechanism whereby cholesterol is converted to cholic acid involves 26-hydroxylated intermediates, and $5 \beta$-cholestane- $3 \alpha, 7 \alpha, 12 \alpha, 26$-tetrol and $3 \alpha, 7 \alpha, 12 \alpha$ trihydroxy- $5 \beta$-cholestanoic acid are postulated as key intermediates in this biosynthetic pathway (2). Loss of the isopropyl group of the side chain follows the forma-

\footnotetext{
${ }^{1}$ Nomenclature: The following systematic names are given to bile acids referred to by trivial names: chenodeoxycholic acid, $3 \alpha, 7 \alpha$-dihydroxy-5 $\beta$-cholanoic acid; cholic acid, $3 \alpha$, $7 \alpha, 12 \alpha$-trihydroxy-5 $\beta$-cholanoic acid.
} 
tion of a 24-hydroxylated intermediate, $3 \alpha, 7 \alpha, 12 \alpha$, $24 \xi$-tetrahydroxy- $5 \beta$-cholestanoic acid, which results in the formation of cholic acid and propionic acid (3).

During the last few years, we have studied the bile acid synthetic defect in the rare, inherited lipid storage disease, cerebrotendinous xanthomatosis (CTX). ${ }^{2}$ This condition is characterized by the extensive accumulation of cholesterol and cholestanol throughout the body with particularly large sterol deposits in the brain, the lung, and the Achilles tendons (4). Symptoms develop secondarily to the location of the xanthomatous deposits. However, defective regulation of hepatic cholesterol and bile acid metabolism has been implicated as the major pathogenic mechanism in this condition (5). Specifically, CTX patients oversynthesize cholesterol and cholestanol, but are unable to produce sufficient quantities of bile acids ( $\cong 50 \%$ of normal). In addition, CTX subjects secrete substantial quantities of bile alcohols in bile and feces, in particular, $5 \beta$-cholestane$3 \alpha, 7 \alpha, 12 \alpha, 25$-tetrol (6). This $5 \beta$-cholestanetetrol has been demonstrated to be a key intermediate in the alternate pathway of cholic acid biosynthesis in CTX and normolipidemic subjects (7). To further investigate the defect in cholic acid synthesis in CTX patients, two putative precursors of cholic acid, namely $5 \beta$-cholestane- $3 \alpha, 7 \alpha, 12 \alpha$-triol and $5 \beta$-cholestane- $3 \alpha, 7 \alpha, 12 \alpha, 24 \mathrm{~S}$, 25 -pentol, were examined by both in vivo and in vitro experiments. The results of these studies clearly show that the site of the enzymatic defect in cholic acid synthesis in CTX is associated with a deficiency of a microsomal enzyme-system catalyzing the conversion of $5 \beta$-cholestane- $3 \alpha, 7 \alpha, 12 \alpha, 25$-tetrol to $5 \beta$-cholestane$3 \alpha, 7 \alpha, 12 \alpha, 24 \mathrm{~S}, 25$-pentol.

\section{METHODS}

Clinical. Studies were conducted in six subjects: two CTX patients, one normolipidemic subject, and three hyper-

${ }^{2}$ Abbreviations used in this paper: CTX, cerebrotendinous xanthomatosis; TLC, thin-layer chromatography. lipidemic individuals (types IIb and IV). The latter four served as controls. Brief clinical summaries are given in Table I, while detailed descriptions of the CTX subjects have been published previously (4). The patients were hospitalized at the East Orange N. J. Veterans Administration Hospital and were fed regular hospital diets. Liver chemistries and blood coagulation tests were normal. Liver biopsies were obtained from J.C. and E.D.S. (CTX) for diagnostic light and electron microscopic examinations (8) and hepatic enzyme analysis. Liver specimens from O.W. and H.J. (controls) were obtained during surgery for chronic peptic ulcer disease (subtotal gastrectomies and vagotomies). The experimental protocol was approved by the Human Study Committee of the East Orange Veterans Administration Hospital, and the College of Medicine and Dentistry of New Jersey, New Jersey Medical School. Informed consent was obtained before surgery. After the induction of anesthesia with Enflurane (Ohio Medical Corp., Dayton, Ohio), the abdomen was opened and liver specimens which weighed 2-4 g were obtained.

Preparation of unlabeled compounds. 5 $\beta$-Cholestane$3 \alpha, 7 \alpha, 12 \alpha$-triol was prepared by electrolytic coupling according to Bergström and Krabisch (9), $5 \beta$-cholestane- $3 \alpha, 7 \alpha, 12 \alpha$, 25 -tetrol was prepared from cholic acid and purified as described by Dayal et al. (10). $5 \beta$-Cholestane- $3 \alpha, 7 \alpha, 12 \alpha, 24 \mathrm{~S}$, 25-pentol (melting point: $203-205^{\circ} \mathrm{C}$ ) was synthesized from $5 \beta$-cholestane- $3 \alpha, 7 \alpha, 12 \alpha, 25$-tetrol as described previously (11).

Preparation of labeled compounds. $5 \beta-\left[7 \beta^{3} \mathrm{H}\right]$ cholestane-3 $\alpha, 7 \alpha, 12 \alpha$-triol was prepared according to Björkhem and Gustafsson (12). Similarly, $5 \beta-\left[7 \beta-{ }^{3} \mathrm{H}\right]$ cholestane- $3 \alpha$, $7 \alpha, 12 \alpha, 25$-tetrol was prepared by $\mathrm{N}$-bromosuccinimide oxidation of $5 \beta$-cholestane- $3 \alpha, 7 \alpha, 12 \alpha, 25$-tetrol and reduction of the resulting 7 -keto compound (purified by preparative thinlayer chromatography [TLC] on silica gel G plates with chloroform:acetone:methanol, 70:50:8 [vol/vol/vol]) with $\left[{ }^{3} \mathrm{H}\right]$ sodium borohydride. $5 \beta-\left[24-{ }^{14} \mathrm{C}\right]$ cholestane- $3 \alpha, 7 \alpha, 12 \alpha$, 24S,25-pentol was prepared according to Salen et al. (13). The final compounds were purified by crystallization from acetone. The following specific activities were obtained: $5 \beta$-cholestane- $3 \alpha, 7 \alpha, 12 \alpha$-triol, $1.61 \times 10^{7} \mathrm{dpm} / \mu \mathrm{mol}$ (radiopurity $97.8 \%$ ); $5 \beta$-cholestane- $3 \alpha, 7 \alpha, 12 \alpha, 25$-tetrol, $1.60 \times 10^{4} \mathrm{dpm} /$ $\mu \mathrm{mol}$ (radiopurity $98.4 \%$ ); and $5 \beta$-cholestane- $3 \alpha, 7 \alpha, 12 \alpha, 24 \mathrm{~S}$, 25-pentol, $1.36 \times 10^{4} \mathrm{dpm} / \mu \mathrm{mol}$ (radiopurity $93.7 \%$ ).

Cofactors. NAD, NADP, NADPH, D-glucose-6-phosphate, and glucose-6-phosphate dehydrogenase were purchased from Calbiochem, San Diego, Calif.

Gas-liquid chromatography. The bile acids and bile alcohols were analyzed as the trimethylsilyl ether derivatives on $180 \times 4-\mathrm{mm}$ columns packed with $3 \%$ methylfluoroalkyl silicone on 80-100 mesh GAS Chrom Q (Ap-

TABLE I

Data on Patients

\begin{tabular}{lccccrrrr}
\hline Patient & Sex & Age & Height & Weight & $\begin{array}{c}\text { \% of ideal } \\
\text { weight }\end{array}$ & \multicolumn{1}{c}{ TC* } & TG 1 & Diagnosis \\
\hline & & & $c m$ & $k g$ & & \multicolumn{2}{c}{$m g / 100 m l$} & \\
J.C. & M & 39 & 165 & 55 & 95 & 144 & 84 & CTX \\
E.D.S. & F & 53 & 161 & 47 & 94 & 132 & 62 & CTX \\
A.S. & M & 55 & 175 & 88 & 135 & 195 & 205 & Hyperlipidemia (type IIb), cholelithiasis \\
J.S. & M & 57 & 168 & 96 & 154 & 309 & 1,008 & Hyperlipidemia (type IV) \\
O.W. & M & 52 & 166 & 66 & 124 & 236 & 253 & Hyperlipidemia (type IIb), chronic peptic ulcer disease \\
H.J. & M & 59 & 196 & 78 & 134 & 211 & 74 & Chronic peptic ulcer disease, (normolipidemic) \\
\hline
\end{tabular}

* TC, total cholesterol.

† TG, triglycerides. 
plied Science Labs. Inc., State College, Pa.) column temperature $230^{\circ} \mathrm{C}$ (gas chromatograph, model 7610, Hewlett-Packard Co., Palo Alto, Calif.) (10).

Mass spectra. Mass spectra of the bile alcohols were obtained with a Varian MAT-III gas chromatograph-mass spectrometer, Varian Associates, Palo Alto, Calif., as described previously (11).

Experimental design in vivo. To study the formation of cholic acid, each one of the labeled precursors, $5 \beta-[7 \beta$ $\left.{ }^{3} \mathrm{H}\right]$ cholestane- $3 \alpha, 7 \alpha, 12 \alpha$-triol and $5 \beta-\left[24-{ }^{14} \mathrm{C}\right]$ cholestane$3 \alpha, 7 \alpha, 12 \alpha, 24 \mathrm{~S}, 25$-pentol, was administered intravenously in separate experiments to two CTX and two control subjects. Labeled cholic acid was isolated from daily specimens of bile, its mass and radioactivity were determined, and the specific radioactivity decay curves were plotted vs. time (14). In addition, $5 \beta-\left[7 \beta-{ }^{3} \mathrm{H}\right]$ cholestane- $3 \alpha, 7 \alpha, 12 \alpha, 25$-tetrol was isolated from the bile specimens of the two CTX patients and the specific radioactivity decay curves were plotted vs. time as described above.

Experimental design in vitro. Liver homogenates of CTX patients and control subjects were fractionated by differential ultracentrifugation and the microsomal and soluble fractions were prepared and incubated separately with the following putative precursors: $5 \beta-\left[7 \beta-{ }^{3} \mathrm{H}\right]$ cholestane- $3 \alpha, 7 \alpha$, $12 \alpha$-triol, $5 \beta-\left[7 \beta^{-3} \mathrm{H}\right]$ cholestane- $3 \alpha, 7 \alpha, 12 \alpha, 25$-tetrol, and $5 \beta$ $\left[24-{ }^{14} \mathrm{C}\right]$ cholestane-3 $\alpha, 7 \alpha, 12 \alpha, 24 \mathrm{~S}, 25$-pentol. After $15 \mathrm{~min}$ of incubation the reaction was stopped and the activities of the different enzymes were determined by a combination of TLCliquid scintillation counting of the pertinent products.

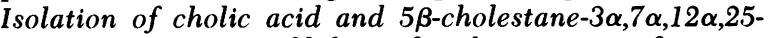
tetrol from specimens of bile. After the injection of a tracer dose of a labeled putative bile acid precursor, labeled cholic acid was isolated from specimens of bile from CTX as well as control subjects; labeled $5 \beta$-cholestane- $3 \alpha, 7 \alpha, 12 \alpha, 25$-tetrol was isolated only from CTX patients as described previously by Salen et al. (14). In a typical experiment, a specimen of bile was made alkaline ( $\mathrm{pH}$ 9.5) and extracted exhaustively with ethyl acetate. $5 \beta$-Cholestane- $3 \alpha, 7 \alpha, 12 \alpha, 25$-tetrol was isolated from the ethyl acetate extract by TLC on silica gel $G$ plates (0.25-mm thick, Analtech, Inc., Newark, Del.) with a solvent system of chloroform:acetone:methanol (70:50:10 [ [ $01 / \mathrm{vol} /$ vol]). The aqueous layer was made strongly alkaline $(2.5 \mathrm{~N}$ $\mathrm{NaOH}$ ) and autoclaved at $115^{\circ} \mathrm{C}$ for $3 \mathrm{~h}$. After acidification (pH 2) the bile acids were extracted with ether. Cholic acid was isolated from the ether extract by TLC on silica gel G plates (Analtech, Inc.) with benzene:dioxane:acetic acid (15:5:2 [vol/vol/vol]). Labeled $5 \beta$-cholestane-3 $\alpha, 7 \alpha, 12 \alpha, 25$ tetrol and cholic acid thus obtained were quantitated by GLC and their radioactivity was determined by liquid scintillation counting (14).

Fractionation of liver homogenates. All specimens of human liver were obtained at about 10:00 a.m. to minimize the diurnal variation of bile acid synthesis. The liver tissue was placed immediately in ice-cold $0.1 \mathrm{M}$ Tris-Cl buffer, $\mathrm{pH}$ 7.4, which contained $2.5 \mathrm{mM}$ EDTA, and was transported to the laboratory in an ice bath within $1 \mathrm{~h}$. All subsequent operations were carried out at $4^{\circ} \mathrm{C}$. The liver was extruded through a tissue press (Harvard Apparatus Co., Inc., Millis, Mass.). A $\mathrm{l}-\mathrm{g}$ aliquot was homogenized in a loose-fitting PotterElvehjem homogenizer with $4 \mathrm{ml}$ of $0.1 \mathrm{M}$ Tris-Cl buffer, $\mathrm{pH}$ 7.4 , which contained $2.5 \mathrm{mM}$ EDTA. The microsomal fraction was obtained by centrifuging the homogenate for $12 \mathrm{~min}$ at $20,000 \mathrm{~g}$, followed by centrifugation at $100,000 \mathrm{~g}$ for $1 \mathrm{~h}$ (15). The microsomal pellet was washed by resuspension in $0.1 \mathrm{M}$ Tris-Cl buffer, pH 7.4, with EDTA, followed by centrifugation for $1 \mathrm{~h}$ at $100,000 \mathrm{~g}$. The final pellet was sus-

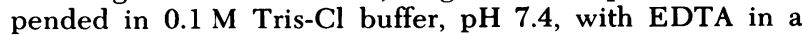

volume corresponding to the original $20,000 \mathrm{~g}$ supernatant solution from which it had been prepared.

Protein was determined according to Lowry et al. (16). The protein content of the microsomal fraction was about $5 \mathrm{mg} / \mathrm{ml}$ and, of the $100,000 \mathrm{~g}$ supernatant fraction, about $12 \mathrm{mg} / \mathrm{ml}$.

\section{Enzyme Assays}

Conversion of $5 \beta$-cholestane- $3 \alpha, 7 \alpha, 12 \alpha$-triol to $5 \beta$-chole-

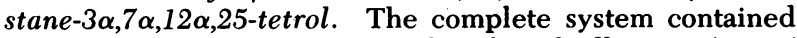
in a volume of $1.0 \mathrm{ml}: 85 \mathrm{mM}$ phosphate buffer, $\mathrm{pH} 7.4,1.7$ $\mathrm{mM} \mathrm{MgCl} 2,3 \mathrm{mM} \mathrm{NADPH}$, and $0.1 \mathrm{ml}$ of the microsomal fraction that contained $1-1.5 \mathrm{mg}$ protein. The reaction was initiated by the addition of $5 \beta-\left[7 \beta-{ }^{3} \mathrm{H}\right]$ cholestane- $3 \alpha, 7 \alpha$, $12 \alpha$-triol (100 nmol, sp act, $\left.1.61 \times 10^{7} \mathrm{dpm} / \mu \mathrm{mol}\right)$ in $15 \mu \mathrm{l}$ acetone. The incubation mixture was shaken in air at $37^{\circ} \mathrm{C}$ for $15 \mathrm{~min}$ and the reaction was terminated by the addition of 0.1 $\mathrm{ml} 1 \mathrm{~N} \mathrm{HCl}$. All enzyme assays were carried out in duplicate and zero time controls were run with each experiment. The unreacted $5 \beta$-cholestane- $3 \alpha, 7 \alpha, 12 \alpha$-triol and the reaction products were immediately extracted with $2 \times 5.0 \mathrm{ml}$ ethyl acetate, shaking for 5 min each time. The combined ethyl acetate extracts were washed twice with water and evaporated to dryness under $\mathrm{N}_{2}$. The $5 \beta-\left[7 \beta^{3} \mathrm{H}\right]$ cholestane- $3 \alpha, 7 \alpha, 12 \alpha$, 25-tetrol formed during the incubation was isolated by TLC as follows: $5 \beta$-cholestane- $3 \alpha, 7 \alpha, 12 \alpha, 25$-tetrol was separated from the other $5 \beta$-cholestanetetrols by TLC on $0.25-\mathrm{mm}$ thick silica gel $\mathrm{G}$ plates (Brinkmann Instruments Inc., Westbury, N. Y.) with chloroform:acetone; methanol (70:50:7 [vol/vol/ vol], developed three times). Unlabeled cholestanetetrols (5 $\mu \mathrm{g}$ each) were applied with the extracts as markers. The pertinent spots were made visible with a spray reagent which consisted of $3.5 \%$ phosphomolybdic acid in isopropanol. Retardation factor values were as follows: $5 \beta$-cholestane$3 \alpha, 7 \alpha, 12 \alpha, 24 \mathrm{R}$-tetrol, $0.35 ; 5 \beta$-cholestane-3 $\alpha, 7 \alpha, 12 \alpha, 25$-tetrol, $0.41 ; 5 \beta$-cholestane-3 $\alpha, 7 \alpha, 12 \alpha, 26$-tetrol (25R), 0.44 ; and $5 \beta$ cholestane- $3 \alpha, 7 \alpha, 12 \alpha, 24 S$-tetrol $+5 \beta$-cholestane-3 $\alpha, 7 \alpha, 12 \alpha$, 26-tetrol (25S), 0.47. Enzyme activity was calculated after removing the spot that corresponded to $5 \beta$-cholestane-3 $\alpha$, $7 \alpha, 12 \alpha, 25$-tetrol from the plate and measuring its radioactivity in a liquid scintillation counter. Because the specific radioactivity of the substrate was known, the radioactivity data could be expressed in terms of pmol of product formed.

To confirm the identity and the radioactive purity of the biosynthetic $5 \beta-\left[7 \beta^{-3} \mathrm{H}\right]$ cholestane- $3 \alpha, 7 \alpha, 12 \alpha, 25$-tetrol, a largescale incubation was carried out and the pertinent band from the preparative silica gel $\mathrm{G}$ plate (Brinkmann Instruments Inc.) was eluted with methanol. The methanol extract was divided into three aliquots: one aliquot was used for mass and structure determination by GLC-mass spectrometry, a second aliquot was used for radioactivity determination in a liquid scintillation counter (Beckman LS-200B, Beckman Instruments, Inc., Fullerton, Calif.), and a third aliquot was reapplied on alumina $\mathrm{G}$ plate $(0.25-\mathrm{mm}$ thick, Analtech, Inc.) and developed with benzene:ethyl acetate:methanol (90:20:14 [vol/vol/vol]). After visualizing the spot with iodine, it was removed from the plate, eluted with methanol, and its mass and radioactivity were determined by GLC and liquid scintillation counting.

Conversion of $5 \beta$-cholestane-3 $\alpha, 7 \alpha, 12 \alpha, 25$-tetrol to $5 \beta$ cholestane - $3 \alpha, 7 \alpha, 12 \alpha, 24 S, 25$ - pentol. $5 \beta-\left[7 \beta-{ }^{3} \mathrm{H}\right]$ choles tane-3 $\alpha, 7 \alpha, 12 \alpha, 25$-tetrol $\left(200 \mathrm{nmol}\right.$; sp act $1.60 \times 10^{4} \mathrm{dpm} /$ $\mu \mathrm{mol}$ ) in methanol was mixed with $0.15 \mathrm{mg}$ of Tween-80 (Fisher Scientific Co., Springfield, N. J.). The organic solvent was evaporated to dryness and the residue was solubilized by vigorous mixing (Vortex Scientific Industries, Inc., Bohemia, N. Y.) in $0.1 \mathrm{ml}$ of $0.1 \mathrm{M}$ Tris-Cl buffer, pH 7.4. In a 
final volume of $1.0 \mathrm{ml}$, the incubation mixture contained: $0.2 \mathrm{mM}$ labeled $5 \beta$-cholestane- $3 \alpha, 7 \alpha, 12 \alpha, 25$-tetrol; $85 \mathrm{mM}$ Tris-Cl buffer, pH 7.4; $1.0 \mathrm{mM}$ EDTA; $1.0 \mathrm{mM}$ NADP; 3.6 $\mathrm{mM}$ glucose-6-phosphate; 7 enzyme $U$ of glucose-6-phosphate dehydrogenase; and $\cong 0.7 \mathrm{mg}$ of microsomal protein. The incubation of the entire system was carried out with shaking for $10 \mathrm{~min}$ at $37^{\circ} \mathrm{C}$ in air and was terminated by the addition of $1.0 \mathrm{ml}$ of $10 \% \mathrm{KOH}$ in methanol: $\mathrm{H}_{2} \mathrm{O}(90: 10$ [vol/ vol]). The $5 \beta-\left[7 \beta-{ }^{3} \mathrm{H}\right]$ cholestane- $3 \alpha, 7 \alpha, 12 \alpha, 24 \mathrm{~S}, 25$-pentol was isolated from the incubation mixture and its radioactivity determined as described by Cheng et al. (17).

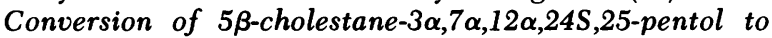
cholic acid. In standard incubation procedures $200 \mathrm{nmol}$ of $5 \beta-\left[24-{ }^{14} \mathrm{C}\right]$ cholestane-3 $\alpha, 7 \alpha, 12 \alpha, 24 \mathrm{~S}, 25$-pentol was dissolved in $30 \mu \mathrm{l}$ of acetone which was quickly dispersed into $0.2 \mathrm{ml} \mathrm{0.1} \mathrm{M} \mathrm{Tris} \mathrm{Cl-buffer,} \mathrm{pH} \mathrm{7.4.} \mathrm{In} \mathrm{a} \mathrm{volume} \mathrm{of} 0.72 \mathrm{ml}$, the incubation medium contained: $83 \mathrm{mM}$ Tris-Cl buffer, $\mathrm{pH}$ $7.4 ; 4.2 \mathrm{mM} \mathrm{NAD}^{+}$; and 100,000 g supernatant solution which contained $\cong 0.5 \mathrm{mg}$ of protein. The incubation was carried out by shaking in air at $37^{\circ} \mathrm{C}$ for $10 \mathrm{~min}$. The reaction was terminated by the addition of $2 \% \mathrm{NaOH}$ in $95 \%$ ethanol. The [24$\left.{ }^{14} \mathrm{C}\right]$ cholic acid formed was isolated and its radioactivity was determined as described previously (7).

\section{RESULTS}

In vivo conversion of $5 \beta-\left[7 \beta-{ }^{3} \mathrm{H}\right]$ cholestane- $3 \alpha$, $7 \alpha, 12 \alpha$-triol to cholic acid. $5 \beta-\left[7 \beta-{ }^{3} \mathrm{H}\right]$ cholestane$3 \alpha, 7 \alpha, 12 \alpha$-triol $(2 \mu \mathrm{Ci})$ was injected intravenously to two control and two CTX subjects. The ${ }^{3} \mathrm{H}$-labeled cholic acid formed was isolated from daily specimens of bile collected over a period of 1 wk and its specific activity decay-curves were plotted as shown in Fig. 1. In all subjects, radioactive cholic acid was detected within $1 \mathrm{~d}$ of pulse labeling. In the controls, maximum specific activity values were reached within $24 \mathrm{~h}$, followed by a linear decay of the cholic acid specific activity curves. In contrast, the maximum specific activity of cholic acid in the CTX patients was reached only $2 \mathrm{~d}$ after pulse labeling and then declined linearly.

More detailed studies of the products formed from the labeled $5 \beta$-cholestane- $3 \alpha, 7 \alpha, 12 \alpha$-triol showed the presence of ${ }^{3} \mathrm{H}$-labeled $5 \beta$-cholestane- $3 \alpha, 7 \alpha, 12 \alpha, 25-$ tetrol in the bile specimens of the CTX patients; this labeled tetrol was absent in the bile of the control subjects. Fig. 2 illustrates the specific activity decay-curves of $5 \beta-\left[7 \beta-{ }^{3} \mathrm{H}\right]$ cholestane- $3 \alpha, 7 \alpha, 12 \alpha, 25$-tetrol and that of ${ }^{3} \mathrm{H}$-labeled cholic acid in one of the CTX patients (E.D.S.). The specific activity decay-curve of the tetrol intersected with the rising specific activity curve of cholic acid, thus showing a precursor-product relationship.

In vivo conversion of $5 \beta$-cholestane- $3 \alpha, 7 \alpha, 12 \alpha$, 24S,25-pentol to cholic acid. After the intravenous injection of $5 \beta-\left[24-{ }^{14} \mathrm{C}\right]$ cholestane- $3 \alpha, 7 \alpha, 12 \alpha, 24 \mathrm{~S}, 25-$ pentol $(2 \mu \mathrm{Ci})$ to two control and two CTX subjects, ${ }^{14} \mathrm{C}$-labeled cholic acid was isolated from daily specimens of bile. The results of this experiment are shown in Fig. 3. Radioactivity was present in the cholic acid

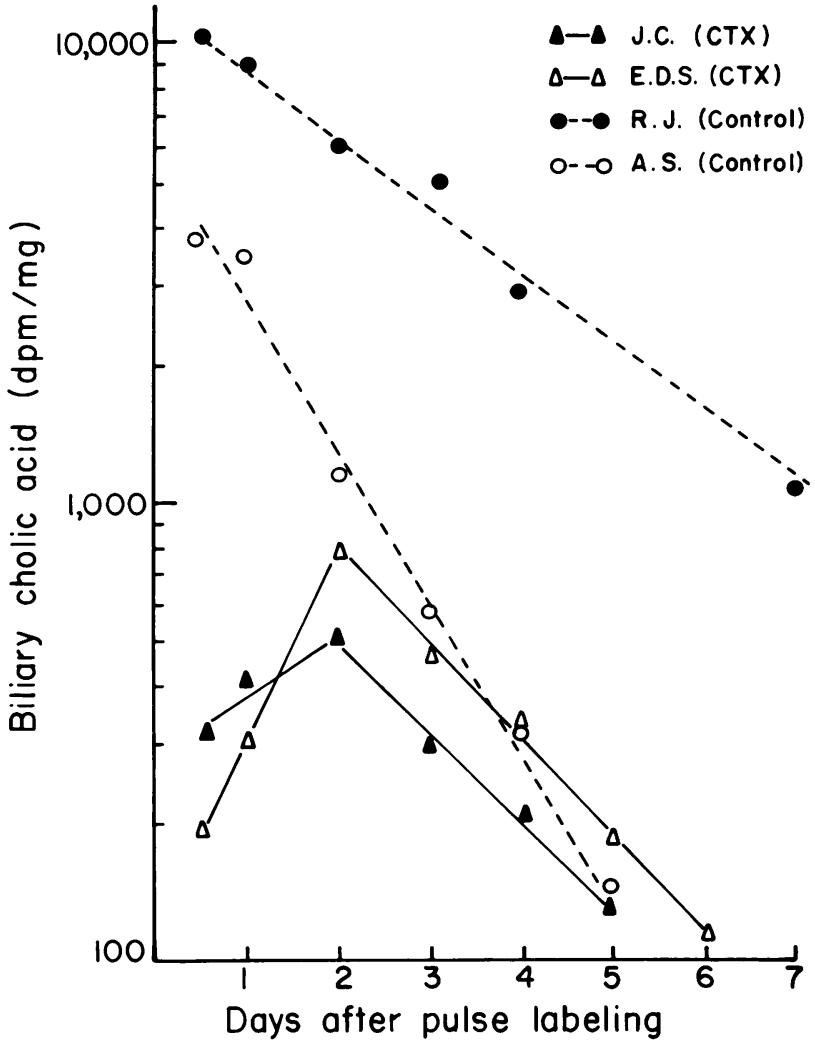

FIGURE 1 Specific activity vs. time decay curves of cholic acid from bile of two normolipidemic and two CTX subjects after intravenous pulse labeling with $5 \beta\left[7 \beta^{3} \mathrm{H}\right] 3 \alpha, 7 \alpha, 12 \alpha$ triol.

from all subjects (controls, as well as CTX patients) and the specific activity vs. time curves decayed exponentially, reaching a maximum within $24 \mathrm{~h}$.

In vitro conversion of $5 \beta$-cholestane- $3 \alpha, 7 \alpha, 12 \alpha$ triol to cholic acid. To examine the individual steps on the pathway from $5 \beta$-cholestane- $3 \alpha, 7 \alpha, 12 \alpha$-triol to cholic acid (Fig. 4), the following reactions were carried out with labeled substrates: $(a)$ conversion of $5 \beta$ cholestane- $3 \alpha, 7 \alpha, 12 \alpha$-triol to $5 \beta$-cholestane- $3 \alpha, 7 \alpha$, $12 \alpha, 25$-tetrol by hepatic microsomes, $(b)$ conversion of $5 \beta$-cholestane-3 $\alpha, 7 \alpha, 12 \alpha, 25$-tetrol to $5 \beta$-cholestane- $3 \alpha$, $7 \alpha, 12 \alpha, 24 \mathrm{~S}, 25$-pentol by hepatic microsomes, and $(c)$ transformation of $5 \beta$-cholestane- $3 \alpha, 7 \alpha, 12 \alpha, 24 \mathrm{~S}, 25-$ pentol to cholic acid by hepatic soluble enzyme preparations. Comparisons were made between subcellular hepatic preparations of control and CTX subjects. The results are illustrated in Table II and show that the enzyme activity catalyzing the 25 -hydroxylation of $5 \beta$-cholestane- $3 \alpha, 7 \alpha, 12 \alpha$-triol to yield $5 \beta$ cholestane-3 $\alpha, 7 \alpha, 12 \alpha, 25$-tetrol was active in both control and CTX subjects. In contrast, the transformation of $5 \beta$-cholestane-3 $\alpha, 7 \alpha, 12 \alpha, 25$-tetrol to $5 \beta$-cholestane- 


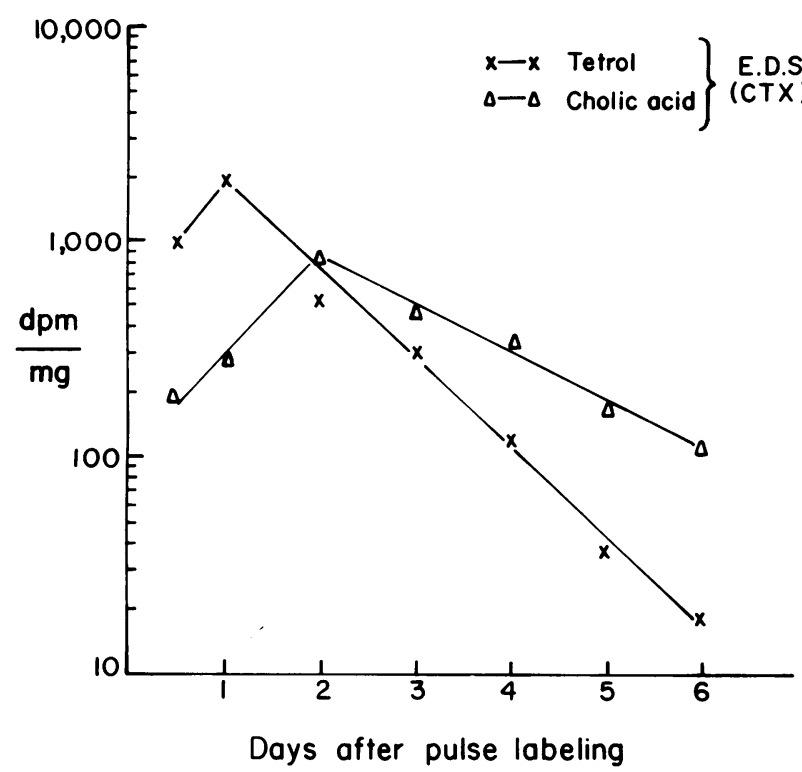

Figure 2 Specific activity vs. time decay curves of $5 \beta$ cholestane- $3 \alpha, 7 \alpha, 12 \alpha, 25$-tetrol and cholic acid isolated from bile of a CTX patient after intravenous pulse labeling with $5 \beta\left[7 \beta-{ }^{3} \mathrm{H}\right] 3 \alpha, 7 \alpha, 12 \alpha$-triol.

$3 \alpha, 7 \alpha, 12 \alpha, 24 \mathrm{~S}, 25$-pentol by hepatic microsomes was four times greater in the control subjects than in the CTX patients. Finally, the rate of the side-chain cleavage of $5 \beta$-cholestane- $3 \alpha, 7 \alpha, 12 \alpha, 24 \mathrm{~S}, 25$-pentol by hepatic soluble enzymes in CTX patients was comparable to that in the controls.

\section{DISCUSSION}

The results of the present investigation show that $5 \beta$-cholestane- $3 \alpha, 7 \alpha, 12 \alpha$-triol, $5 \beta$-cholestane- $3 \alpha, 7 \alpha, 12 \alpha$, 25-tetrol, and $5 \beta$-cholestane- $3 \alpha, 7 \alpha, 12 \alpha, 24 S, 25$-pentol were converted into cholic acid in both control and CTX subjects. In the control subjects, $5 \beta$-cholestane$3 \alpha, 7 \alpha, 12 \alpha$-triol was rapidly transformed to cholic acid so that peak cholic acid specific activity was detected within the first $24 \mathrm{~h}$ after pulse labeling. In contrast, the specific activity of biliary cholic acid in the CTX subjects rose slowly over the first $24 \mathrm{~h}$ and did not reach a maximum value until $48 \mathrm{~h}$ after pulse labeling (Fig. 1). When this transformation was examined more closely in one of the CTX subjects, a characteristic precursorproduct relationship between biliary cholic acid and $5 \beta$-cholestane- $3 \alpha, 7 \alpha, 12 \alpha, 25$-tetrol was observed (Fig. 2 ), which implies that most of the cholic acid originated from this tetrol (18). Furthermore, no $5 \beta$-cholestane$3 \alpha, 7 \alpha, 12 \alpha$-triol was detected in the bile of this CTX patient which suggests a rapid and complete conversion of this triol to cholic acid via $5 \beta$-cholestane$3 \alpha, 7 \alpha, 12 \alpha, 25$-tetrol. After $5 \beta-\left(24-{ }^{14} \mathrm{C}\right)$ cholestane- $3 \alpha, 7 \alpha$, $12 \alpha, 24 \mathrm{~S}, 25$-pentol was administered, peak biliary

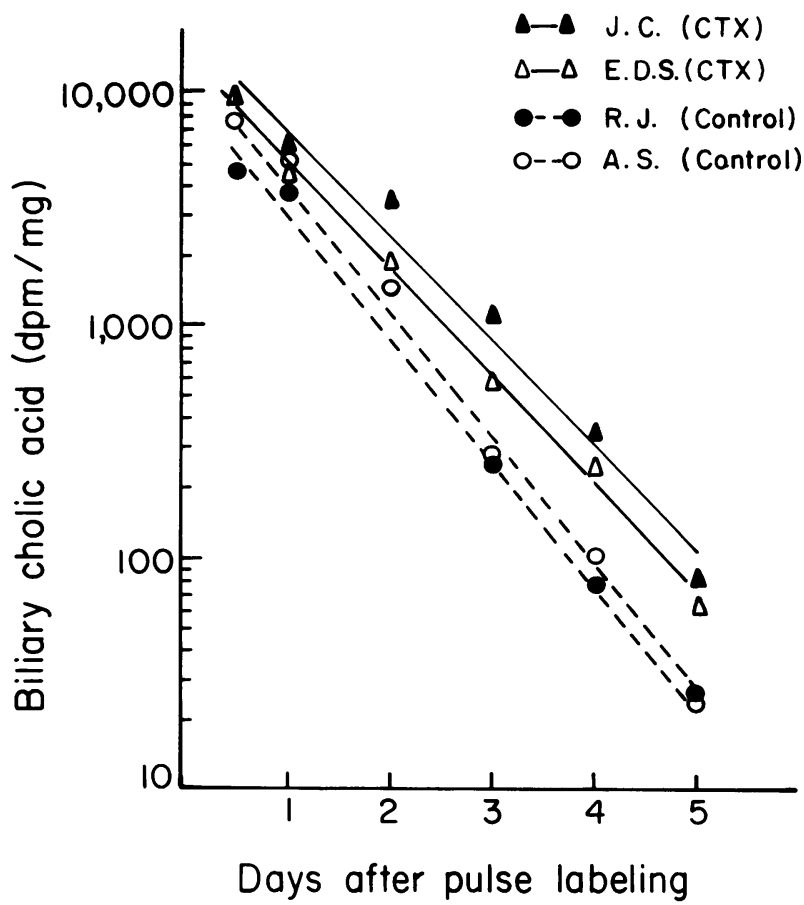

FIGURE 3 Specific activity vs. time decay curves of cholic acid from bile of two normolipidemic and two CTX subjects after intravenous pulse labeling with $5 \beta\left[24-{ }^{14} \mathrm{C}\right] 3 \alpha, 7 \alpha, 12 \alpha$, 24S,25-pentol.

cholic acid specific activities were reached within $24 \mathrm{~h}$ in both the CTX and control subjects; followed by similar exponential decay curves of radioactive cholic acid.

The results of the in vivo experiments (vide supra) indicate that in both CTX and control subjects there was no block in the formation of cholic acid from $5 \beta$ cholestane-3 $\alpha, 7 \alpha, 12 \alpha, 24 \mathrm{~S}, 25$-pentol, whereas the transformation of $5 \beta$-cholestane- $3 \alpha, 7 \alpha, 12 \alpha$-triol to
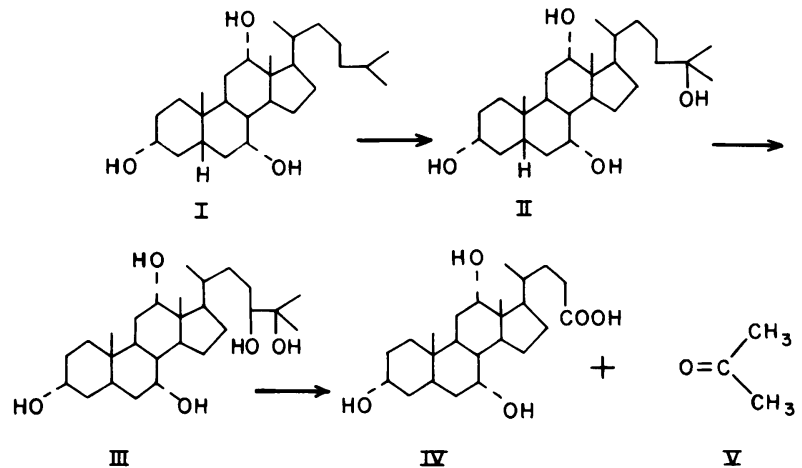

FIgure 4 Pathway of cholic acid biosynthesis showing side chain degradation via 25 -hydroxylated intermediates. I, $5 \beta$ cholestane- $3 \alpha, 7 \alpha, 12 \alpha$-triol; II, $5 \beta$-cholestane- $3 \alpha, 7 \alpha, 12 \alpha, 25$ tetrol; III, $5 \beta$-cholestane-3 $\alpha, 7 \alpha, 12 \alpha, 24 S, 25$-pentol; IV, cholic acid; $\mathrm{V}$, acetone. 
TABLE II

The Activity of Enzymes on the 25-Hydroxylation Pathway

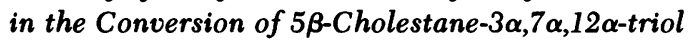

to Cholic Acid*

\begin{tabular}{lcc}
\hline & \multicolumn{2}{c}{ Rate of product formation } \\
\cline { 2 - 3 } Enzyme & Control & CTX \\
\hline $\begin{array}{c}25 \text {-hydrox- } \\
\text { ylase } \$\end{array}$ & $5,480(5,631 ; 5,329)$ & $7,110(7,320 ; 6,900)$ \\
$\begin{array}{c}24 \text { S-hydrox- } \\
\text { ylase }\end{array}$ & $636(670 ; 602)$ & $151(143 ; 159)$ \\
$\begin{array}{c}\text { Cleavage } \\
\text { enzyme }\end{array}$ & $9,160(9,008 ; 9,312)$ & $7,310(7,560 ; 7,058)$ \\
\hline
\end{tabular}

* Microsomal and soluble fractions were prepared and products were analyzed as described in Methods.

$\$$ Enzyme catalyzing the conversion of $5 \beta$-cholestane- $3 \alpha$, $7 \alpha, 12 \alpha$-triol (I, Fig. 4) to $5 \beta$-cholestane-3 $\alpha, 7 \alpha, 12 \alpha, 25$-tetrol (II).

$\$$ Enzyme catalyzing the conversion of $5 \beta$-cholestane- $3 \alpha$, $7 \alpha, 12 \alpha, 25$-tetrol (II) to $5 \beta$-cholestane- $3 \alpha, 7 \alpha, 12 \alpha, 24 \mathrm{~S}, 25$-pentol (III).

"Enzymes catalyzing the conversion of $5 \beta$-cholestane$3 \alpha, 7 \alpha, 12 \alpha, 24 \mathrm{~S}, 25$-pentol (III) to cholic acid (IV).

Average values with individual determinations in parenthesis.

cholic acid was hindered in the CTX patients and was associated with the accumulation of $5 \beta$-cholestane$3 \alpha, 7 \alpha, 12 \alpha, 25$-tetrol. Thus, defective $24 \mathrm{~S}$-hydroxylation of $5 \beta$-cholestane- $3 \alpha, 7 \alpha, 12 \alpha, 25$-tetrol appears to be the enzymatic abnormality which causes the deficiency of cholic acid in CTX. This possibility was supported by the results of the in vitro incubation experiments with hepatic microsomal and soluble enzyme preparations (Table II). When $5 \beta$-cholestane- $3 \alpha, 7 \alpha, 12 \alpha$-triol was incubated with hepatic microsomes prepared from control as well as CTX liver specimens, active 25hydroxylation was observed in both cases with the

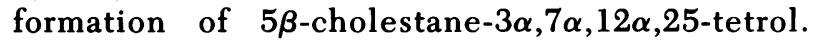
Similarly, the cleavage of $5 \beta$-cholestane- $3 \alpha, 7 \alpha, 12 \alpha$, 24S,25-pentol to yield cholic acid by the soluble enzyme fractions was comparable in both cases. In contrast, the rate of $24 \mathrm{~S}$-hydroxylation of $5 \beta$-cholestane$3 \alpha, 7 \alpha, 12 \alpha, 25$-tetrol by hepatic microsomes from CTX patients was only 0.25 of that from the controls. Thus, a complete 25-hydroxylation pathway of cholic acid from $5 \beta$-cholestane- $3 \alpha, 7 \alpha, 12 \alpha$-triol is demonstrated in CTX as well as control subjects (Fig. 4). However, 24S-hydroxylase activity is depressed in CTX and apparently results in the accumulation of $5 \beta$-cholestane$3 \alpha, 7 \alpha, 12 \alpha, 15$-tetrol. Although small amounts of $5 \beta$ cholestane-3 $\alpha, 7 \alpha, 12 \alpha, 24 \mathrm{R}, 25$-pentol and $5 \beta$-cholestane-3 $\alpha, 7 \alpha, 12 \alpha, 23 \xi, 25$-pentol were formed by hepatic microsomes (17) and were found in the feces and bile of CTX subjects (11), neither bile alcohol is converted to cholic acid (7). We postulate that both compounds accumulate in CTX subjects because deficient 24Shydroxylation prolongs the exposure of $5 \beta$-cholestane$3 \alpha, 7 \alpha, 12 \alpha, 25$-tetrol to the microsomal $24 \mathrm{R}$ - and 23 hydroxylation systems.

The block in bile acid synthesis may be related to the development of the clinical picture in CTX. Brain, tendon, and lung xanthomas and coronary atherosclerosis are the major clinical manifestations that result from the excessive deposition of cholesterol and cholestanol in these vital tissues. Recently, we have presented evidence that the increased, neutral sterol deposits result from the overproduction of both cholesterol and cholestanol (5). However, because CTX is inherited as an autosomal recessive disease, the genetic defect should result from a single enzyme defect which must account directly or indirectly for all the clinical and biochemical aspects of this hereditary metabolic disease (19). The demonstration that bile acid synthesis is abnormal with a specific defect in 24S-hydroxylation of $5 \beta$-cholestane- $3 \alpha, 7 \alpha, 12 \alpha, 25$-tetrol fits well into the definition of a recessively inherited genetic disease. As a result of diminished bile acid pool, cholesterol production increases; but, because of the block in side-chain cleavage, bile acid precursors are excreted and the augmented cholesterol production is only partially converted to bile acids. The remainder is available for deposition in the tissues and for cholestanol formation.

\section{ACKNOWLEDGMENTS}

The skillful technical assistance of Ms. S. Hauser and Ms. D. Verga is gratefully acknowledged.

This work was supported by U. S. Public Health Service grants AM-18707, HL-17818, and AM-19696.

\section{REFERENCES}

1. Danielsson, H. 1973. In The Bile Acids. P. P. Nair and D. Kritchevsky, editors. Plenum Publishing Corporation, New York. 2: 1-32, 305-306.

2. Björkhem, I., J. Gustafsson, G. Johansson, and B. Persson. 1975. Biosynthesis of bile acids in man. Hydroxylation of steroid side chain. J. Clin. Invest. 55: 478-486.

3. Masui, T., and E. Staple. 1966. The formation of bile acids from cholesterol. The conversion of $5 \beta$-cholestane- $3 \alpha$, $7 \alpha, 12 \alpha$-triol-26-oic acid to cholic acid via $5 \beta$-cholestane$3 \alpha, 7 \alpha, 12 \alpha, 24 \xi$-tetrol-26-oic acid by rat liver.J. Biol. Chem. 241: 3889-3893.

4. Salen, G. 1971. Cholestanol deposition in cerebrotendinous xanthomatosis. A possible mechanism. Ann. Intern. Med. 75: 843-851.

5. Salen, G., and S. M. Grundy. 1973. The metabolism of cholestanol, cholesterol, and bile acids in cerebrotendinous xanthomatosis. J. Clin. Invest. 52: 2822-2835.

6. Setoguchi, T., G. Salen, G. S. Tint, and E. H. Mosbach. 1974. A biochemical abnormality in cerebrotendinous xanthomatosis. Impairment of bile acid biosynthesis associated with incomplete degradation of the cholesterol side chain. J. Clin. Invest. 53: 1393-1401. 
7. Shefer, S., F. W. Cheng, B. Dayal, S. Hauser, G. S. Tint, G. Salen, and E. H. Mosbach. 1976. A 25-hydroxylation pathway of cholic acid biosynthesis in man and rat. $J$. Clin. Invest. 57: 897-903.

8. Salen, G., S. Shefer, F. G. Zaki, and E. H. Mosbach. 1977. Inborn errors of bile acid synthesis. Clin. Gastroenterol. 6: $91-101$.

9. Bergström, S., and L. Krabisch. 1957. Preparation of some hydroxycoprostanes; $3 \alpha, 7 \alpha$ - and $3 \alpha, 12 \alpha$-dihydroxycoprostane. Bile acids and steroids 49. Acta Chem. Scand. Ser. B. Org. Chem. Biochem. 11: 1067.

10. Dayal, B., S. Shefer, G. S. Tint, G. Salen, and E. H. Mosbach. 1976. Synthesis of $5 \beta$-cholestane- $3 \alpha, 7 \alpha, 12 \alpha$, 25-tetrol and $5 \beta$-cholestane-3 $\alpha, 7 \alpha, 12 \alpha, 24 \xi, 25$-pentol. $J$. Lipid Res. 17: 74-77.

11. Shefer, S., B. Dayal, G. S. Tint, G. Salen, and E. H. Mosbach. 1975. Identification of pentahydroxy bile alcohols in cerebrotendinous xanthomatosis: characterization of $5 \beta$-cholestane- $3 \alpha, 7 \alpha, 12 \alpha, 24 \xi, 25$-pentol and $5 \beta$-cholestane- $3 \alpha, 7 \alpha, 23 \xi, 25$-pentol. J. Lipid Res. 16: 280-286.

12. Björkhem, I., and J. Gustafsson. 1973. $\omega$-Hydroxylation of steroid side chain in biosynthesis of bile acids. Eur. J. Biochem. 36: 201-212.

13. Salen, G., S. Shefer, F. W. Cheng, B. Dayal, and E. H.
Mosbach. 1976. The role of C-25 hydroxylated bile alcohols as precursors of cholic acid in man. In The Liver: Quantitative Aspects of Structure and Function. R. Preisig, J. Bircher, and G. Paumgartner, editors. Cantor Press Aulentors. 220-226.

14. Salen, G., S. Shefer, T. Setoguchi, and E. H. Mosbach. 1975. Bile acid metabolism in man. Conversion of $5 \beta$ cholestane-3 $\alpha, 7 \alpha, 12 \alpha, 25$-tetrol to cholic acid. J. Clin. Invest. 56: 226-231.

15. Danielsson, H., and K. Einarsson. 1966. On the conversion of cholesterol to $7 \alpha, 12 \alpha$-dihydroxycholest-4-en-3-one. J. Biol. Chem. 241: 1449-1454.

16. Lowry, O. H., N. J. Rosebrough, A. L. Farr, and R. J. Randall. 1951. Protein measurement with the Folin phenol reagent. J. Biol. Chem. 193: 265-275.

17. Cheng, F. W., S. Shefer, B. Dayal, G. S. Tint, T. Setoguchi, G. Salen, and E. H. Mosbach. 1977. Cholic acid biosynthesis: conversion of $5 \beta$-cholestane- $3 \alpha, 7 \alpha, 12 \alpha, 25-$ tetrol into $5 \beta$-cholestane- $3 \alpha, 7 \alpha, 12 \alpha, 24 \beta, 25$-pentol by human and rat liver microsomes. J. Lipid Res. 18: 6-12.

18. Reiner, J. M. 1974. Recent advances in molecular pathology. Isotopic analysis of metabolic systems. Exp. Mol. Pathol. 20: 78-108.

19. Landing, B. H. 1960. Symposium on hereditary metabolic diseases. Hereditary metabolic diseases-general considerations. 9: 198-207. 